\title{
Progesterone induction of calcitonin expression in the murine mammary gland
}

\author{
P M Ismail, F J DeMayo, P Amato ${ }^{1}$ and J P Lydon \\ Department of Molecular and Cellular Biology, Baylor College of Medicine, One Baylor Plaza, Houston, Texas 77030, USA \\ ${ }^{1}$ Department of Obstetrics and Gynecology, Baylor College of Medicine, One Baylor Plaza, Houston, Texas 77030, USA \\ (Requests for offprints should be addressed to J P Lydon; Email: jlydon@bcm.tmc.edu)
}

\begin{abstract}
Progesterone, via its nuclear receptor, is mandatory not only for the induction and specification of mammary gland ductal side-branching and lobuloalveologenesis but also for carcinogen-induced mammary tumorigenesis. Notwithstanding these recent advances, a more comprehensive molecular explanation of progesterone-induced mammary morphogenesis is contingent upon the identification and characterization of mammary molecular targets that are responsive to the progesterone signal. Toward this goal, we report that calcitonin, a 32 amino acid peptide hormone involved in calcium homeostasis, is exclusively expressed in, and secreted from, luminal epithelial cells within the
\end{abstract}

mammary gland of the pregnant mouse, and, importantly, its expression is progesterone-dependent. Conversely, the calcitonin receptor is present during all stages of post-natal mammary development examined, is localized to the myoepithelial cell lineage, and is not regulated by progesterone. Because calcitonin induction spatiotemporally correlates with increases in progesterone-induced mammary gland proliferation and structural remodeling, we posit that calcitonin - through its receptor - may be involved in one or both of these progesterone-dependent processes.

Journal of Endocrinology (2004) 180, 287-295

\section{Introduction}

Utilizing a progesterone receptor (PR) knockout (PRKO) mouse, in which both isoforms of $\mathrm{PR}$ (PR-A and $-\mathrm{B}$ ) were simultaneously ablated through gene-targeting approaches, we previously demonstrated that the progesterone proliferative signal is essential for pregnancy-associated ductal side-branching and alveologenesis (Lydon et al. 1995, Soyal et al. 2002). Of importance to breast cancer, removal of the progesterone proliferative signal resulted in a marked reduction in susceptibility of the PRKO mouse to carcinogen-induced mammary tumorigenesis (Lydon et al. 1999, Chatterton et al. 2002, Medina et al. 2003), supporting an essential role for progesterone and its downstream effectors in breast cancer etiology. This latter proposal agrees with recent clinical studies demonstrating that combined estrogen and progesterone (EP) postmenopausal hormone replacement therapies increase breast cancer beyond the risk presented by estrogen treatment alone (Schairer et al. 2000). Previous mammary gland transplantation approaches, immunohistochemistry, and more recently the PR-LacZ knockin reporter, have revealed that the progesterone signal emanates exclusively from a subset of luminal epithelial cells in the murine mammary gland (Silberstein et al. 1996, Brisken et al. 1998, Seagroves et al. 2000, Ismail et al. 2002). Moreover, the observation that luminal epithelial cells expressing PR are segregated from, but are in close apposition to, epithelial cells that undergo progesterone-induced proliferation (Seagroves et al. 2000, Ismail et al. 2002), suggests a paracrine mode of action for progesterone in this tissue. A similar mechanism of action has also been proposed to underlie progesterone-induced proliferation in the rat and human mammary gland (Clarke et al. 1997, Russo et al. 1999).

Despite recent advances in our understanding of progesterone's role in mammary gland development and tumorigenesis, it remains a challenge to mechanistically define the paracrine pathways through which the PR mediates the progesterone signal. A more comprehensive molecular explanation of progesterone's action in the mammary gland must await the identification and characterization of downstream molecular targets that are directly or indirectly modulated by progesterone.

Previously, calcitonin (CT), a 32 amino acid peptide hormone involved in calcium homeostasis (Sexton et al. 1999, Pondel 2000), was identified as a uterine molecular target transiently and specifically induced by progesterone in the early pregnant rat, baboon and human (Ding et al. 1994, Kumar et al. 1998, 2003). Outside the brain, most of the physiological effects of CT are transduced by the CT receptor (CTR) C1a subtype, a member of a superfamily of heptahelical membrane-spanning $G$ protein-coupled receptors (Brown et al. 1996). Interestingly, this receptor 
superfamily includes the receptor for the peptide hormone, parathyroid hormone-related protein (PTHrP) (Brown et al. 1996); like CT, PTHrP exhibits potent controls on calcium homeostasis (Dunbar et al. 1996), but also exerts a pivotal role in mammary gland development and function (Wysolmerski et al. 1995). As a corollary to the above, osteoprotegrin ligand (OPGL), which is also involved in bone homeostasis, was recently shown to play a critical role in mammary alveologenesis (Fata et al. 2000); interestingly, mammary OPGL expression has been shown to be modulated (in part) by progesterone (Fata et al. 2000, Mulac-Jericevic et al. 2003).

Of further significance, CT and CTR have been detected in human breast cancer cell lines (Findlay et al. 1981, Kurokawa et al. 1991) and in primary breast cancers (Gillespie et al. 1997), suggesting that aberrant expression of the CT signaling pathway may confer upon breast cancer cells a selective growth advantage and/or an ability to undergo metastasis to other target tissues, such as bone; this latter suggestion is based on CT's previously described bone-resorbing functions (Sexton et al. 1999). Recently, the induction of CT and CTR transcripts was detected in the normal mammary gland of the pregnant rat, but not in the virgin gland (Tverberg et al. 2000), suggesting that one or more pregnancy hormones may modulate the emergence of this signaling pathway in the rat mammary gland. Based on the above, the mouse - in particular the PRKO mouse - was employed to evaluate whether CT and CTR are expressed in the murine mammary gland, and if so, to determine whether their expression is responsive to the endocrine mammogenic effects of progesterone.

\section{Materials and Methods}

\section{Mice and hormone treatment}

Mice, with a C57BL6/129SvJ mixed genetic background, were maintained in a temperature-controlled room $\left(22 \pm 2{ }^{\circ} \mathrm{C}\right)$ with a $12 \mathrm{~h}$ light: $12 \mathrm{~h}$ darkness photocycle and fed rodent chow meal (Purina Mills, Inc., St Louis, MO, USA) and fresh water, freely available. The PRKO mouse model has been previously described (Lydon et al. 1995).

For total RNA isolation and immunohistochemistry, mammary glands (both thoracics and inguinals) were dissected from mice at various stages of mammary development: virgin (12 weeks old), pregnancy (days 2, 4, 6, 8, 12 and 18), lactation (day 7) and involution (day 7); for timed pregnancies, the morning of observing the vaginal plug was designated as day 0.5 of pregnancy. Tissues were processed for immunohistochemistry or snap frozen on dry ice for RNA isolation.

To elicit ductal side-branching and initial alveologenesis in the intact virgin mouse (12 weeks old), EP (estrogen $(1 \mu \mathrm{g})$ and progesterone $(1 \mathrm{mg})$ (in sesame oil) in combination) was administered by daily intrascapular s.c. injections for 7 days, according to procedures described previously (Said et al. 1997).

\section{$R N A$ and immunohistochemistry}

The RNase protection assay (RPA) was performed using the RPA III kit according to the manufacturer's instructions (Ambion, Inc., Austin, TX, USA); mammary gland RNA isolation was previously described (Lydon et al. 1999). The murine CT RPA probe, obtained from the American Type Culture Collection (ATCC), Manassas, VA, USA (ATCC number 1213716), encompassed 350 bp localized within exon 4 of the murine CT gene (Thomas et al. 2001). For each developmental time point or hormone treatment group, the CT mean transcript induction ( \pm s.E.M.) is presented as a percentage of cyclophilin message from five separate experiments; four mice per time point or hormonetreatment group were used in the RNA and immunohistochemical assays described herein. Radioactive signals from protected fragments were quantified on a Storm 860 Phosphor Imager (Molecular Dynamics, Inc., Sunnyvale, CA, USA), standardized relative to cyclophilin and represented as an average of five experiments \pm S.E.M.

For immunohistochemistry, mammary glands were fixed overnight in Bouin's fixative, followed by thorough washing in $70 \%$ ethanol before tissues were processed, embedded in paraffin, and sectioned. CT immunohistochemistry was performed using a rabbit polyclonal antibody to human CT, which cross-reacts with murine CT (NCL-CALp; Novocastra Laboratories Ltd, Newcastle upon Tyne, UK). Immunohistochemistry for PR expression and 5-bromo-2deoxyuridine (BrdU) incorporation is described elsewhere (Lydon et al. 1999). CTR immunohistochemistry was undertaken using a goat polyclonal antibody raised against the amino terminus of the mouse CTR C1a subtype (Santa Cruz Biotechnology, Inc., Santa Cruz, CA, USA). For dual immunofluorescence, a rabbit anti-mouse cytokeratin 14 (Covance Research Products, Inc., Berkeley, CA, USA) was used in concert with the CTR primary antibody using previous methods (Seagroves et al. 2000). To visualize resultant immunocomplexes, donkey anti-goat IgG secondary antibody linked to fluorescein isothiocyanate (green) and donkey anti-rabbit IgG secondary antibody conjugated to Texas Red (red) were used to detect cytokeratin 14 and CTR respectively (Jackson ImmunoResearch Laboratories, Inc., West Grove, PA, USA). All mouse experimental procedures were approved by the Institutional Animal Care and Use Committee of Baylor College of Medicine and were in accordance with the procedures detailed in the 'Guide for Care and Use of Laboratory Animals' (NIH publication 85-23).

\section{Results}

By the second day of pregnancy, RPA detected CT transcript induction in the murine mammary gland 

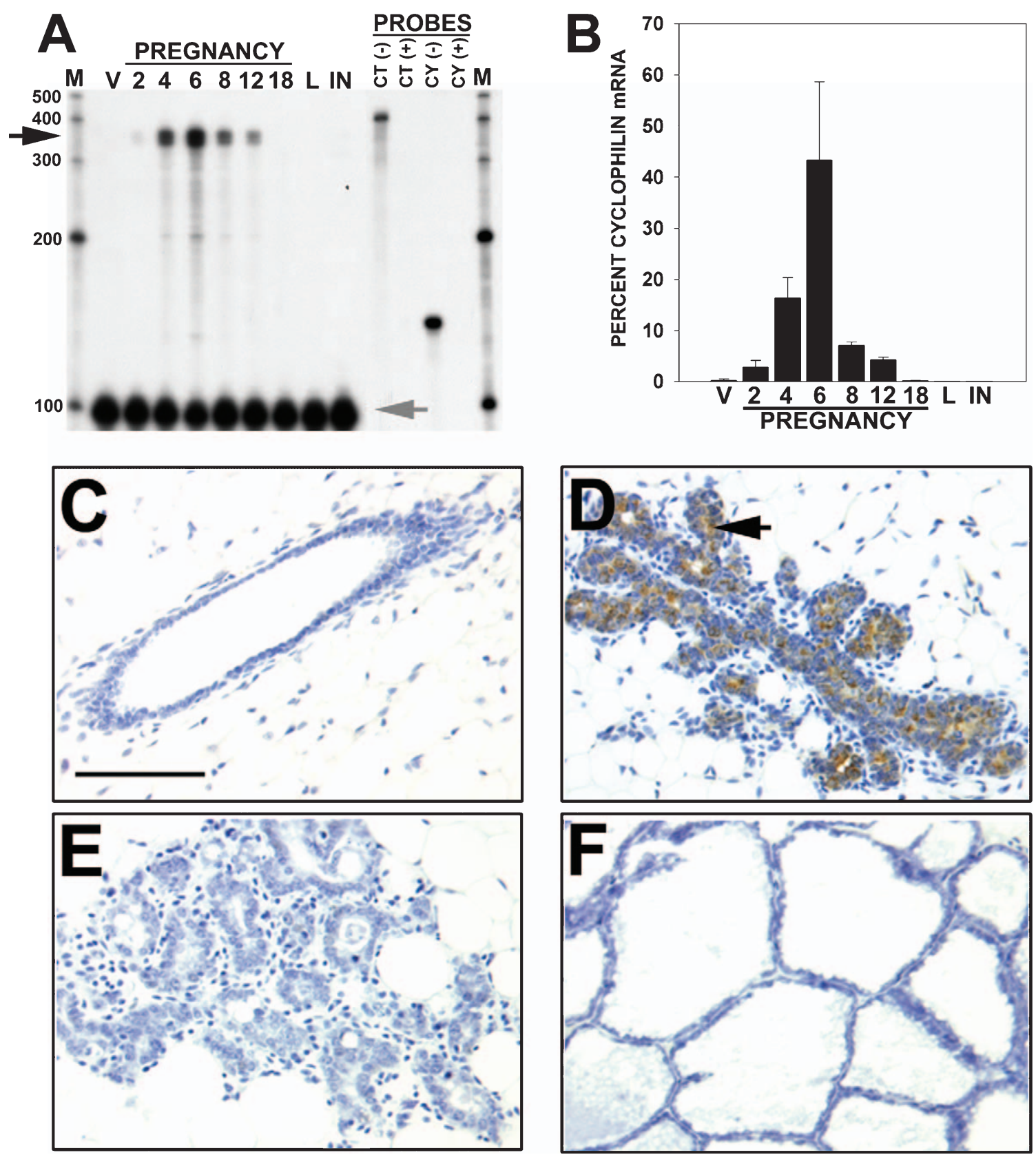

Figure 1 Parity-induced CT expression in the murine mammary gland. RPA for mammary CT expression is shown in (A) for the 12-week-old virgin mouse (V), during days 2, 4, 6, 8, 12 and 18 of pregnancy, and on day 7 of lactation (L) and involution (IN). CT transcripts are induced in the mammary gland as early as day 4 of pregnancy (black arrow; protected fragment: $350 \mathrm{bp}$ ), with maximal transcript levels occurring around day 6 of pregnancy. Mammary CT expression was not detected toward the end of pregnancy (day 18), or during the stages of lactation and involution. Cyclophilin was included as a loading control (gray arrow; protected fragment: $100 \mathrm{bp}$ ). Indicated on the right-side of the gel are probe controls in the presence of yeast RNA consisting of CT or cyclophilin (CY) antisense probes in the absence $(-)$ or presence $(+)$ of RNase. Both marker lanes are denoted by $\mathrm{M}$. The graph in (B) quantitatively displays the induction of $\mathrm{CT}$ expression (shown in (A)) as a percentage of cyclophilin mRNA. CT immunohistochemical analysis of the mammary gland of the 12-week-old virgin, pregnant mouse (day 6), late pregnant mouse (day 18) and of the lactating mouse (day 7 ) is shown in that order in (C-F). Note the induction of CT expression is restricted (arrow) to the mammary epithelial compartment of the parous mouse (D). Scale bar in (C) measures $100 \mu \mathrm{m}$ and also applies to (D-F). The RPA and immunohistochemical data are representative of five separate experiments in which four mice per time point were used for each experiment (20 mice per developmental time point in total). 

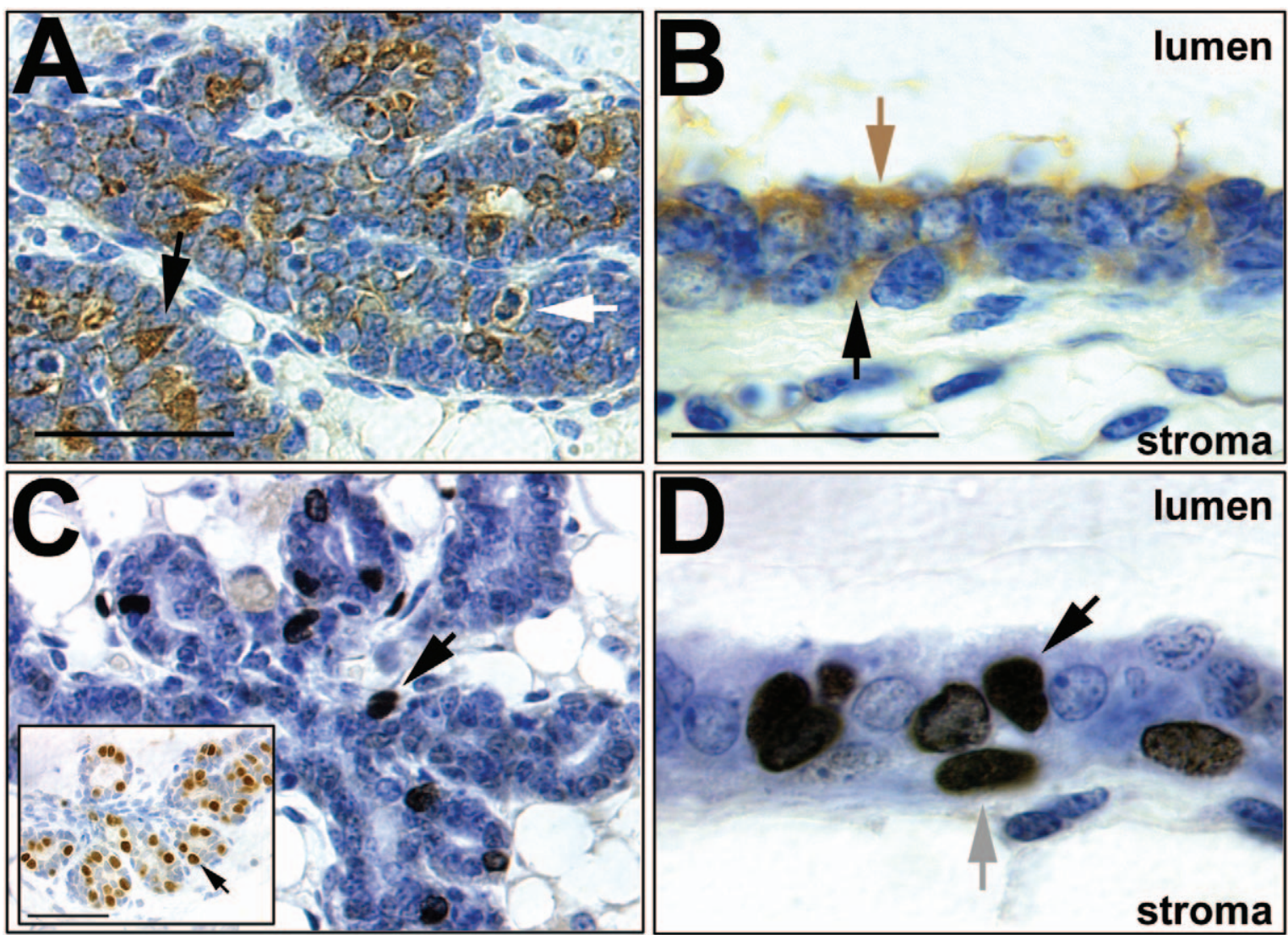

Figure 2 CT is exclusively expressed in and secreted from the luminal epithelial cell lineage of the mammary gland of the parous mouse. (A) High-magnification of Fig. 1D reveals that mammary luminal epithelial cells express and secrete CT (black arrow). Note the mitotic figure (white arrow) in the luminal epithelial compartment, indicative of an actively proliferating tissue. (B) Higher magnification of a longitudinal section of a duct in (A) reveals the presence of CT in the luminal (brown arrow) and in the luminal-myoepithelial region (black arrow). (C) reveals significant BrdU incorporation (black arrow) in the mammary gland of the 6-day pregnant mouse. Inset shows numerous luminal epithelial cells that express PR (black arrow) at this time. (D) Is a higher magnification of a longitudinal section shown in (C) clearly showing luminal (black arrow) and myoepithelial (gray arrow) proliferation. Scale bar in (A) equals $50 \mu \mathrm{m}$ and also applies to panel (C); scale bar in inset denotes $50 \mu \mathrm{m}$, whereas scale bar in (B) indicates $20 \mu \mathrm{m}$ and also applies to (D).

(Fig. 1A and B). The highest levels of CT expression were reached by days 4-6 of pregnancy, only to decline by mid-pregnancy (day 12) to levels observed on day 2 of pregnancy. Mammary transcripts for CT were detected neither during the later time points of pregnancy (day 18) nor during the stages of lactation (day 7) and involution (day 7). As in the rat (Tverberg et al. 2000), CT expression was not detected in the mammary gland of the 12-weekold virgin mouse; however, unlike the rat, CT expression was restricted to the first half of pregnancy in the mouse. Immunohistochemistry confirmed that the virgin mammary gland did not express CT protein (Fig. 1C); however, significant CT expression was detected in the mammary gland of the 6-day pregnant mouse (Fig. 1D (arrow)). As expected, CT protein was not detected in the mammary gland of the late-pregnant mouse (day 18) or of the lactating mouse (Fig. 1E and $\mathrm{F}$ respectively); CT immunoreactivity was not observed in the involuting mammary gland (data not shown).

Close scrutiny of the mammary gland of the 6-day pregnant mouse revealed that the luminal epithelial cell was the cell of origin for CT expression and secretion (Fig. $2 \mathrm{~A}$; black arrow). In concordance with this observation, pro-CT protein was recently detected in the ductal lumen of the human mammary gland (Struck et al. 2002), further supporting mammary CT as a product of the luminal epithelial cell lineage. Although CT was derived from luminal epithelial cells, the secreted protein was detected both in the ductal lumen and in the luminal-myoepithelial junctional region (Fig. 2B; brown and black arrows respectively); however, CT was not detected in periductal fibroblasts or in the outer stromal compartment. The striking increase in CT expression in the mammary luminal epithelial cell of a 6-day pregnant mouse closely 

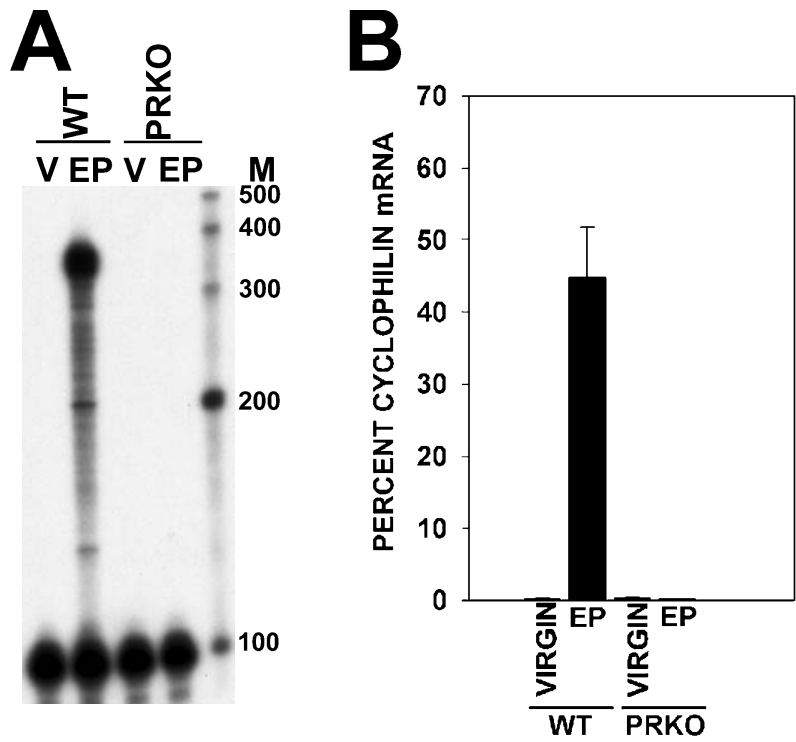

Figure 3 (A) RPA demonstrates that CT is induced within 7 days of EP treatment in the WT virgin (V) but not in the similarly treated PRKO mouse. The graph in (B) shows the quantification of $\mathrm{CT}$ induction (shown in (A)) as a percentage of the loading control, cyclophilin; error bar denotes S.E.M. The RPA data are representative of five experiments in which four mice per hormone treatment and genotype were examined per experiment (20 mice per hormone treatment and genotype in total).

paralleled the noticeable increase in pregnancy-induced proliferation of the luminal and myoepithelial cell at this time (Fig. 2C and D). The increase in mammary epithelial $\mathrm{CT}$ expression and proliferation correlates with robust PR expression (inset in Fig. 2C) at this stage of mammary development, an observation consistent with recent PRLacZ knockin studies (Ismail et al. 2002). Future studies, using alternative approaches (such as CT in situ hybridization analysis coupled with PR immunohistochemistry), will aim to determine whether the subgroup of luminal epithelial cells that express the PR are the cells of origin for $\mathrm{CT}$ expression and secretion.

Because mammary gland CT expression was restricted to the first half of murine pregnancy, we evaluated whether progesterone, through the PR, specifically induced CT in the mammary gland. In response to a 7-day daily treatment of estrogen and progesterone, mammary CT transcripts were induced in the adult wild type (WT) virgin but not in the similarly treated PRKO (Fig. 3A and $\mathrm{B})$, demonstrating that progesterone, not estrogen, is responsible for the induction of $\mathrm{CT}$ expression, and that this induction is mediated by the PR; similar findings have been reported for the uterus (Ding et al. 1994, Kumar et al. 1998, 2003).

As observed during early pregnancy, CT protein induction correlated with an increase in luminal epithelial cell proliferation in the EP-treated WT mouse (Fig. 4; compare $A$ and $B$ with $C$ and $D)$. Interestingly, despite the presence of $\mathrm{PR}$ in the virgin gland (Fig. 4E), mammary CT is not expressed at this developmental stage (Fig. 4A), supporting an obligate role for ligand-dependent activity for $\mathrm{PR}$ in the induction of $\mathrm{CT}$ expression (Fig. 4B). Unlike progesterone-treatment alone (Ismail et al. 2002), a 7-day EP treatment did not suppress PR expression in the mammary gland (Fig. 4F); estrogen is included to maintain PR levels.

To support the concept that an intact CT signaling pathway may be operative in the mammary gland, CTR expression was evaluated during the salient stages of mammary gland development. Unlike CT, CTR is expressed in the virgin mammary gland (Fig. 5A) and is restricted to the myoepithelial cell lineage (black arrow); CTR is not expressed in the luminal cell (red arrow). CTR is present during all stages of mammary development including the later stages of pregnancy (day 18) (Fig. $5 \mathrm{~B}$ ); Fig. $5 \mathrm{C}$ and $\mathrm{D}$ are higher magnifications of $\mathrm{A}$ and $\mathrm{B}$ respectively. To further confirm that CTR expression is limited to the myoepithelial cell lineage (and not to periductal fibroblasts), dual immunofluorescence for cytokeratin 14 (Fig. 5E) and CTR (Fig. 5F) was performed; cytokeratin 14 is a cellular marker for the myoepithelial cell (Smith et al. 1990). In the case of a longitudinal section of a main epithelial duct, Fig. 5G demonstrates that CTR coexpresses with cytokeratin 14 in the myoepithelial cell type (white arrow).

\section{Discussion}

During the onset of pregnancy, the pre-implantation uterus and mammary gland undergo striking changes in proliferation and structural remodeling, both of which are critically dependent on PR function (Soyal et al. 2002). In the case of the PRKO mammary gland, removal of the progesterone proliferative signal abrogates both tertiary ductal side-branching and lobuloalveologenesis (Lydon et al. 1995). Because this specific stage of progesteroneinduced mammary morphogenesis occurs during pregnancy and because an early or late first pregnancy differentially impacts the life-long risk for breast cancer (Henderson et al. 1993), delineating the downstream signaling pathways through which progesterone induces these morphological changes is of paramount importance. Toward this goal, RPA and immunohistochemical approaches in combination with the PRKO mouse unequivocally demonstrated that progesterone, through its receptor, can induce CT expression in the luminal epithelial cell of the murine mammary gland. In contrast, immunohistochemistry revealed that CTR is localized to the myoepithelial cell lineage and its expression is not affected by progesterone. The difference in the temporal expression profiles for CT and CTR between the mouse and rat reflects a fundamental difference in mammary physiology in these two rodent species. 

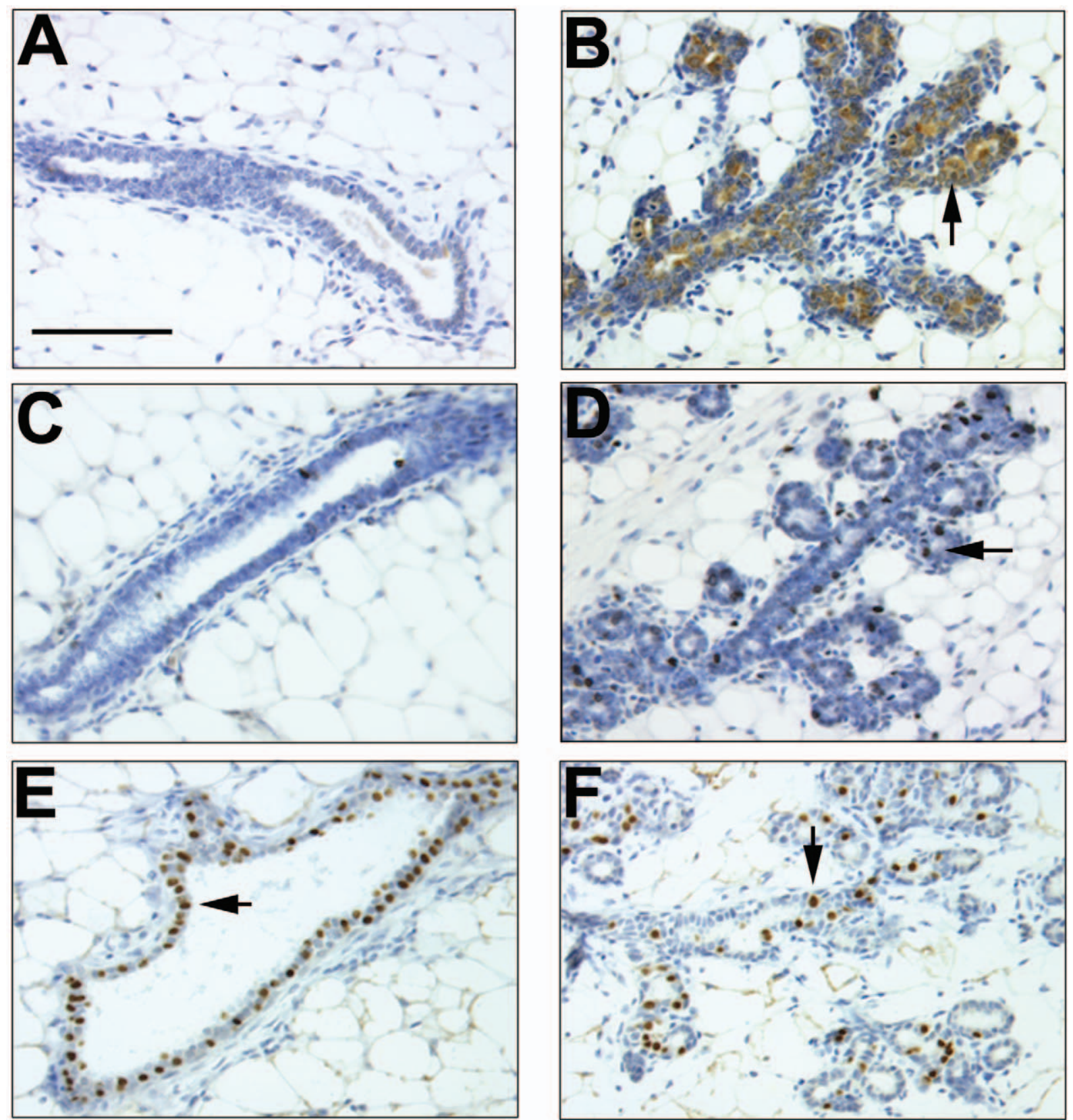

Figure 4 The PR requires progesterone to induce CT expression and luminal epithelial proliferation in the murine mammary gland. $(\mathrm{A}, \mathrm{C}$, and $\mathrm{E})$ Correspond to the 12-week-old virgin mouse, whereas (B, D and F) represent the 7-day EP-treated age-matched virgin. Panels (A and B), (C and D) and (E and F) show $C T$, BrdU, and PR immunoreactivity respectively. Note the increase in $C T$ protein expression in response to EP treatment (compare (A) with (B) (arrow)) which correlates with an increase in the proliferative status of the gland, as judged by an increase in cellular BrdU incorporation (compare (C) with (D) (arrow)). In (E), note that PR expression alone (arrow) is not sufficient to induce CT expression (compare (A and E) with (B and F)). Scale bar in (A) denotes $100 \mu \mathrm{m}$ and applies to all panels.

The restricted expression of CT and CTR to the luminal and myoepithelial cell lineages respectively raises a number of important points.

First, like the uterus (the archetypal progesterone target tissue), an intact CT signaling pathway may be intrinsic to the murine mammary epithelium; however, this assumption has yet to be functionally validated.

Secondly, if future studies demonstrate a functional mammary CT signaling pathway, the segregation of CT and CTR expression at the cellular level would suggest 

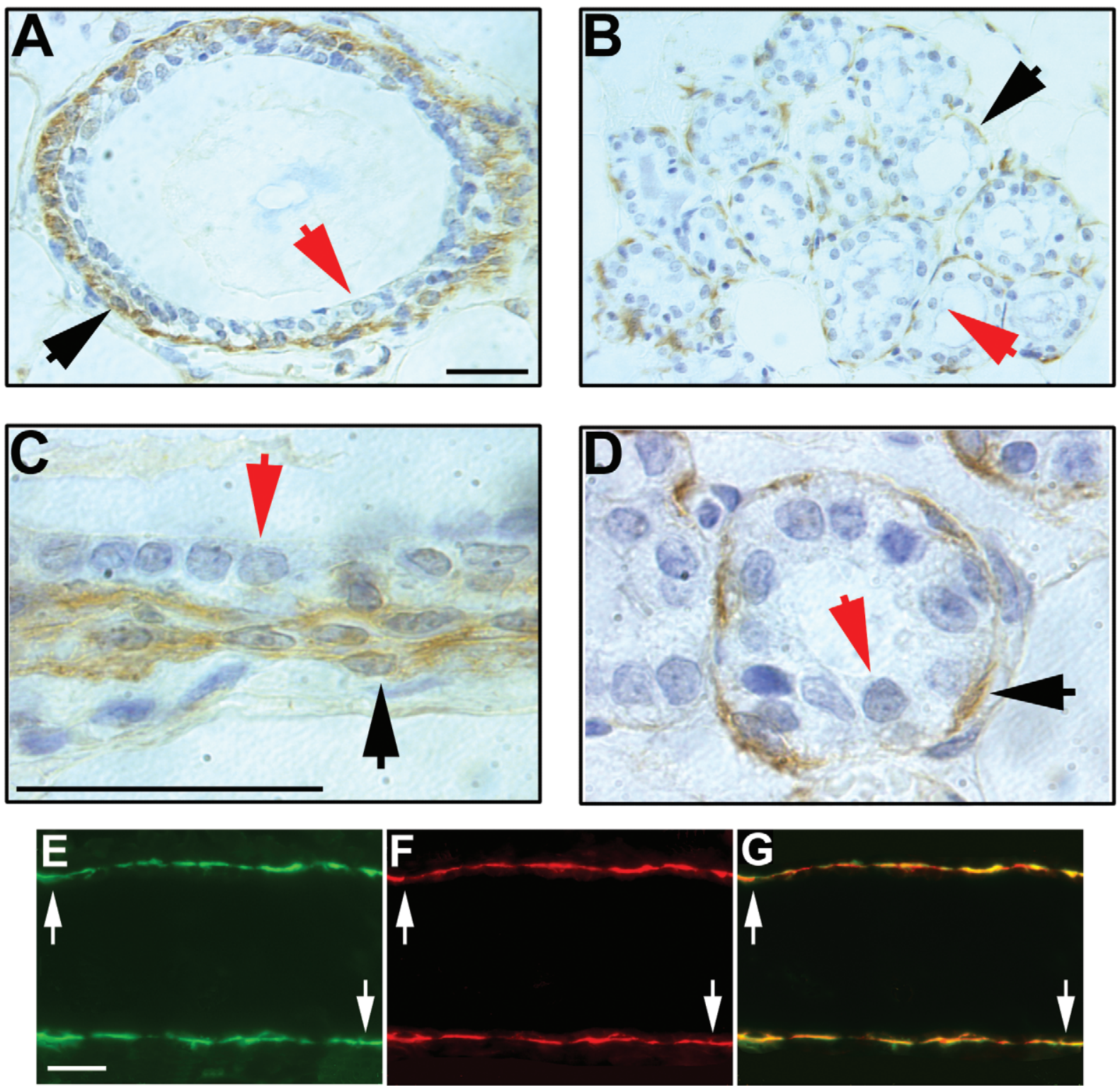

Figure 5 Immunohistochemistry reveals CTR expression is limited to the myoepithelial cell lineage (black arrow) of the mammary gland of the 12-week-old virgin (A) and mid-pregnant mouse (B); unlike CT, CTR is not expressed in the luminal epithelial compartment (red arrow). Higher magnifications of (A) and (B) are shown in (C) and (D) respectively. Double immunofluorescence for the cytokeratin 14 (E) and CTR (F) confirms CTR expression is confined to the myoepithelial cell lineage: in the longitudinal section of a typical medial duct, $(\mathrm{G})$ represents the overlay of $(\mathrm{E})$ and $(\mathrm{F})$ and clearly shows cellular co-expression for both proteins in the myoepithelial cellular compartment (white arrow). Scale bar in (A) and (C) denotes $50 \mu \mathrm{m}$ and applies to (B) and (D) also. Scale bar in (E) represents $20 \mu \mathrm{m}$ and also applies to (F) and (G).

that progesterone could instigate a molecular dialog between the myo- and luminal epithelial cell lineages. That CT could act as a paracrine mediator in such a dialog is supported by the fact that: (i) uterine CT was shown to exert its effects through a paracrine circuit during murine embryo implantation, with maternally derived CT and embryo-derived CTR making up this circuit (Wang et al.
1998); (ii) in the anterior pituitary gland, CT acts as a paracrine signaling pathway between the gonadotrope and lactotrope cell types to suppress prolactin secretion (Ren et al. 2001); (iii) the closely related PTHrP also makes up a paracrine signaling pathway that is indispensable for early mammary development (Wysolmerski et al. 1995); and (iv) progesterone - an upstream affecter of CT expression 
in the mammary gland and uterus - is known to exert its functional effects through paracrine mechanisms in both target tissues (Brisken et al. 1998, Kurita et al. 1998).

Thirdly, the detection of CTR expression in neoplastic mammary luminal epithelial cells in culture (Kurokawa et al. 1991) and in primary mammary tumors (Gillespie et al. 1997) implies that CTR induction within the luminal epithelial lineage (instead of the myoepithelial cell) may be linked to neoplastic transformation of this cell type - the most prevalent form of breast cancer. Extending this notion further, abnormal CTR expression in the luminal cell lineage could conceivably set in train an autocrine circuit for CT signaling, clearly at odds with the proposed paracrine pathway for CT signaling in the normal mammary gland. Indeed, previous PR immunolocalization studies on estrogen receptor/PR-positive human mammary tumors suggest that progesteroneinduced luminal epithelial proliferation may switch from a paracrine signaling pathway in the normal mammary gland to an autocrine loop in neoplastic tissue (Clarke et al. 1997).

Collectively, the data suggest that the functional influence of the progesterone signal may extend (via the CT signaling pathway) to the myoepithelial cell lineage, at a time when the mammary gland is undergoing progesterone-induced mammary proliferation and tissue remodeling. Although speculative, it is not inconceivable that for normal progesterone-induced luminal epithelial cell proliferation to occur in the mammary gland, the myoepithelial compartment may need to receive a progesterone signal (via $\mathrm{CT}$ ) to proliferate and reorganize to accommodate the increase in the number of luminal epithelial cells arising from the progesterone proliferative signal. To achieve this myoepithelial reorganization, CT may act by altering local cellular calcium homeostasis. Changes in calcium levels are known to impact cell-cell adhesion (Sjaastad \& Nelson 1997), thus the hypocalcemic effects of CT may control the disassembly of cellular junctional complexes within the myoepithelial compartment to facilitate the extensive structural remodeling that occurs in the mammary gland during pregnancy or in response to EP treatment. Moreover, a recent report documenting CT modulation of uterine E-cadherin (Li et al. 2002) could represent an additional mechanism by which CT disassembles mammary epithelial junctional complexes.

The foregoing speculations must be tempered, however, by the recent observation that the CT knockout (CTKO) mouse (Hoff et al. 2002) does not exhibit overt defects in fertility or mammary development; a knockout for CTR has yet to be reported. Although the absence of a mammary phenotype in the CTKO mouse argues that $\mathrm{CT}$ is not required per se for normal mammary development, the data do not exclude the possibility that parallel progesterone-dependent signaling pathways compensate for CT's absence (considering progesterone's pivotal role in mammary morphogenesis, built-in degeneracy downstream of the PR would not be surprising). Moreover, with the emergence of receptor-activity modifying proteins (McLatchie et al. 1998, Christopoulos et al. 1999, Sexton et al. 2001), the possibility that mammary CTR may project all or part of its downstream effects independently of CT ligand must be considered, especially in light of the marked difference in spatiotemporal expression profiles for mammary CT and CTR.

Irrespective of the possible mechanisms of $\mathrm{CT}$ action in the mammary gland, we report the expression and cellular localization of CT and its receptor in the murine mammary gland. Importantly, as previously documented for the uterus, progesterone (via PR) specifically induces mammary gland CT expression, which is the first reported target gene regulated by progesterone in both the uterus and mammary gland. Apart from attempting to address an acknowledged insufficiency in our mechanistic understanding of progesterone's role in mammary gland morphogenesis and function, this study underscores the importance of further delineating the molecular nature of the cross-talk that exists between progesterone and CT signaling pathways in vivo, particularly in light of the continued use of these hormones in postmenopausal treatments.

\section{Acknowledgements}

The authors thank S Li and J Li for technical assistance in the immunohistochemical and RPA studies respectively.

\section{Funding}

This work was funded in part by grants from the National Institutes of Health (CA77530) and from the Department of Defense Breast Cancer Research Program IDEA Award DAMD 17-01-1-0138 to JPL and from the Baylor Cancer Center Pilot Grant Program to P A. The authors affirm that a conflict of interest does not arise from their involvement in the research described herein.

\section{References}

Brisken C, Park S, Vass T, Lydon JP, O’Malley BW \& Weinberg RA 1998 A paracrine role for the epithelial progesterone receptor in mammary gland development. PNAS 95 5076-5081.

Brown EM, Segre GV \& Goldring SR 1996 Serpentine receptors for parathyroid hormone, calcitonin and extracellular calcium ions. Baillieres Clinical Endocrinology and Metabolism 10 123-161.

Chatterton RT Jr, Lydon JP, Mehta RG, Mateo ET, Pletz A \& Jordan VC 2002 Role of the progesterone receptor (PR) in susceptibility of mouse mammary gland to 7,12-dimethylbenz [a]anthracene-induced hormone-independent preneoplastic lesions in vitro. Cancer Letters 188 47-52.

Christopoulos G, Perry KJ, Morfis M, Tilakaratine N, Gao Y, Fraser NJ, Main MJ, Foord SM \& Sexton PM 1999 Multiple amylin receptors arise from receptor activity-modifying protein interaction with the calcitonin receptor gene product. Molecular Pharmacology 56 235-242. 
Clarke RB, Howell A, Potten CS \& Anderson E 1997 Dissociation between steroid receptor expression and cell proliferation in the human breast. Cancer Research 57 4987-4991.

Ding YQ, Zhu LJ, Bagchi MK \& Bagchi IC 1994 Progesterone stimulates calcitonin gene expression in the uterus during implantation. Endocrinology 135 2265-2274.

Dunbar ME, Wysolmerski JJ \& Broadus AE 1996 Parathyroid hormone-related protein: from hypercalcemia of malignancy to developmental regulatory molecule. American Journal of Medical Science 312 287-294.

Fata JE, Kong YY, Li J, Sasaki T, Irie-Sasaki J, Moorehead RA, Elliot Scully S, Voura EB, Lacey DL, Boyle WJ et al. 2000 The osteoclast differentiation factor osteoprotegrin-ligand is essential for mammary gland development. Cell 103 41-50.

Findlay DM, Michelangeli VP, Moseley JM \& Martin TJ 1981 Calcitonin binding and degradation by two cultured human breast cancer cell lines (MCF7 and T 47D). Biochemical Journal 196 513-520.

Gillespie MT, Thomas RJ, Pu ZY, Zhou H, Martin TJ \& Findlay DM 1997 Calcitonin receptors, bone sialoprotein and osteopontin are expressed in primary breast cancers. International Journal of Cancer 73 812-815.

Henderson BE, Ross RK \& Pike MC 1993 Hormonal chemoprevention of cancer in women. Science 259 633-638.

Hoff AO, Lehnen C, Thomas PM, Priemel M, Rueger JM, Nasonkin I, Bradley A, Hughes MR, Ordonez N, Cote GJ et al. 2002 Increased bone mass is an unexpected phenotype associated with deletion of the calcitonin gene. Journal of Clinical Investigation $1101849-1857$.

Ismail PM, Li J, DeMayo FJ, O’Malley BW \& Lydon JP 2002 A novel lac $Z$ reporter mouse reveals complex regulation of the progesterone receptor promoter during mammary gland development. Molecular Endocrinology 16 2475-2489.

Kumar S, Zhu L-J, Polihronis M, Cameron ST, Baird DT, Schatz F, Dua A, Ying Y-K, Bagchi MK \& Bagchi IC 1998 Progesterone induces calcitonin gene expression in human endometrium within the putative window of implantation. Journal of Clinical Endocrinology and Metabolism 83 4443-4450.

Kumar S, Brudney A, Cheon YP, Fazleabas AT \& Bagchi IC 2003 Progesterone induces calcitonin expression in the baboon endometrium within the window of uterine receptivity. Biology of Reproduction 68 1318-1323.

Kurita T, Young P, Brody JR, Lydon JP, O'Malley BW \& Cunha GR 1998 Stromal progesterone receptors mediate the inhibitory effects of progesterone on estrogen-induced uterine epithelial cell deoxyribonucleic acid synthesis. Endocrinology 139 4708-4713.

Kurokawa M, Michelangeli VP \& Findlay DM 1991 Induction of calcitonin receptor expression by glucocorticoids in T47D human breast cancer cells. Journal of Endocrinology 130 321-326.

Li Q, Wang J, Armant DR, Bagchi MK \& Bagchi IC 2002 Calcitonin down-regulates E-cadherin expression in rodent uterine epithelium during implantation. Journal of Biological Chemistry 277 46447-46455.

Lydon JP, DeMayo FJ, Funk CR, Mani SK, Hughes AR, Montgomery CA Jr, Shyamala G, Conneely OM \& O'Malley BW 1995 Mice lacking progesterone receptors exhibit pleiotropic reproductive abnormalities. Genes and Development 9 2266-2278.

Lydon JP, Ge G, Kittrell FS, Medina D \& O’Malley BW 1999 Murine mammary gland carcinogenesis is critically dependent on progesterone receptor function. Cancer Research 59 4276-4284.

McLatchie LM, Fraser NJ, Main MJ, Wise A, Brown J, Thompson N, Solari R, Lee MG \& Foord SM 1998 RAMPs regulate the transport and ligand specificity of the calcitonin-receptor-like receptor. Nature 393 333-339.

Medina D, Kittrell FS, Shepard A, Contreras A, Rosen JM \& Lydon J 2003 Hormone dependence in premalignant mammary progression. Cancer Research 63 1067-1072.
Mulac-Jericevic B, Lydon JP, DeMayo FJ \& Conneely OM 2003 Defective mammary gland morphogenesis in mice lacking the progesterone receptor B isoform. PNAS 100 9744-9749.

Pondel M 2000 Calcitonin and calcitonin receptors: bone and beyond. International Journal of Experimental Pathology 81 405-422.

Ren Y, Chien J, Sun YP \& Shah GV 2001 Calcitonin is expressed in gonadotropes of the anterior pituitary gland: its possible role in paracrine regulation of lactotrope function. Journal of Endocrinology 171 217-228.

Russo J, Ao X, Grill C \& Russo IH 1999 Pattern of distribution of cells positive for estrogen receptor- $\alpha$ and progesterone receptor in relation to proliferating cells in the mammary gland. Breast Cancer Research and Treatment 53 217-227.

Said TK, Conneely OM, Medina D, O’Malley BW \& Lydon JP 1997 Progesterone, in addition to estrogen, induces cyclin D1 expression in the murine mammary epithelial cell, in vivo. Endocrinology 138 3933-3939.

Schairer C, Lubin J, Troisi R, Sturgeon S, Brinton L \& Hoover R 2000 Menopausal estrogen and estrogen-progestin replacement therapy and breast cancer risk [see comments]. Journal of the American Medical Association 283 485-491.

Seagroves TN, Lydon JP, Hovey RC, Vonderhaar BK \& Rosen JM $2000 \mathrm{C} / \mathrm{EBP} \beta$ (CCAAT/enhancer binding protein) controls cell fate determination during mammary gland development. Molecular Endocrinology 14 359-368.

Sexton PM, Findlay DM \& Martin TJ 1999 Calcitonin. Current Medicinal Chemistry 6 1067-1093.

Sexton PM, Albiston A, Morfis M \& Tilakaratne N 2001 Receptor activity modifying proteins. Cellular Signalling 13 73-83.

Silberstein GB, Van Horn K, Shyamala G \& Daniel CW 1996 Progesterone receptors in the mouse mammary duct: distribution and developmental regulation. Cell Growth and Differentiation 7 945-952.

Sjaastad MD \& Nelson WJ 1997 Integrin-mediated calcium signaling and regulation of cell adhesion by intracellular calcium. BioEssays 19 47-55.

Smith GH, Mehrel T \& Roop DR 1990 Differential keratin gene expression in developing, differentiating, preneoplastic, and neoplastic mouse epithelium. Cell Growth and Differentiation 1 161-170.

Soyal S, Ismail PM, Li J, Mulac-Jericevic B, Conneely OM \& Lydon JP 2002 Progesterone receptors - animal models and cell signaling in breast cancer: progesterone's role in mammary gland development and tumorigenesis as disclosed by experimental mouse genetics. Breast Cancer Research 4 191-196.

Struck J, de Almeida P, Bergmann A \& Morgenthaler NG 2002 High concentrations of procalcitonin but not mature calcitonin in normal human milk. Hormones and Metabolic Research 34 460-465.

Thomas PM, Nasonkin I, Zhang HZ, Gagel RF \& Cote G 2001 Structure of the mouse calcitonin/calcitonin gene-related peptide alpha and beta genes. DNA Sequence 12 131-135.

Tverberg LA, Gustafson MF, Scott TL, Arzumanova IV, Provost ER, Yan AW \& Rawie SA 2000 Induction of calcitonin and calcitonin receptor expression in rat mammary tissue during pregnancy [In Process Citation]. Endocrinology 141 3696-3702.

Wang J, Rout UK, Bagchi IC \& Armant DR 1998 Expression of calcitonin receptors in mouse preimplantation embryos and their function in the regulation of blastocyst differentiation by calcitonin. Development 125 4293-4302.

Wysolmerski JJ, McCaughern-Carucci JF, Daifotis AG, Broadus AE \& Philbrick WM 1995 Overexpression of parathyroid hormone-related protein or parathyroid hormone in transgenic mice impairs branching morphogenesis during mammary gland development. Development 121 3539-3547.

Received 16 August 2003

Accepted 24 October 2003 